\title{
IDENTIFIKASI KETIDAKSTABILAN SPEKTROMETER GAMMA RSG-GAS DAN CARA MENANGGULANGINYA
}

\author{
Subiharto, Anto Setiawanto, Nugraha Luhur, Nazly Kurniawan \\ Pusat Reaktor Serba Guna-BATAN \\ Kawasan Puspiptek, Gd 3I, Serpong, Tangerang-Selatan \\ subihatto@batan.go.id
}

\begin{abstract}
ABSTRAK
IDENTIFIKASI KETIDAKSTABILAN SPEKTROMETER GAMMA RSG-GAS DAN CARA MENANGGULANGINYA. Telah dilakukan identifikasi ketidakstabilan spcktrometer gamma RSG-GAS dan cara menanggulanginya Spektrometer gamma sdalah salab satu peralatan proteksi radiasi yang dimiliki oleh RSG-GAS, yang digunakan untuk mienganalisis kandungan nuklida yang terdapat dalam air primer. limbah cair dan udara. Keberadaan alat ini merupakan tanggung jawab Sub Bidang Pengendalian Daerah Kerja (PDK). karema sesuai dengan salah satu tusi PDK yaitu molakukan pengelolaan laboraturium proleksi radiasi. Setelah dioperasikari sclama 26 tahurn alat mi rerkadang penurifukkannya tidak stabil, dan ktidak representatif. Oleh karena itu perlu dilakukan identitikasi permasalahan spektrometer gamma RSG-GAS dan dicari eara penanggulangannya agar diketahui secara pasti kemampuan kincrjanya. 1dentifikasi dilakukan dengan cara melakukan pemeriksaan Hardware, Sottware dan dikiuti dengan pengukuran sampel dan sumber standar, Berdasarkan hasil Identifikasi yang dilakukan dapat dikctahui bahwa penyebab ketidakstabilan spektrometer gamma RSG-GAS adalah karenj sering terlambat dalam melakukan pendinginan dam melemahnya unjuk kerja Amplifier. Setelah pendinginan selalu dikondisikan dengan baik dan dilakukan penggantian rerhadap Amplifier maku spektrometer gamma RSG.GAS berada dalam kondisi normal kembali.
\end{abstract}

Ilmu dan Kata kunci : Idertifikasi dan ketidakstabilan, spektrometer gamma, RSG-GAS

\section{ABSTRACT}

IDENTIFICATION OF GIMMA SPECTROMETER INSTABILITS AND ITS COUNTERMEASURES. It has heen carried out the idthitification of gamma specirometer instahility and its countermeasures. Gamma speetrometer is one of the radiction prafection supporting equipments which belongs to G. A. Siwabessy Multipurpose Reactor. Ganma spectrometer is operated in perform the radionuclider analysis th the reactor primary cooling atalcr, liquid waste, and in the wir. This cquipment is under she responsibility of the warking area controlling subdivision, becanse it is in Avcordance nuth the abse of the working artea controlling subdirision, which wo manage the radiarion protection laboratory. Unth this time, thix gamma spectrometer Thes been operated for 26 years. and it shous several problems such as; counting instability and the counting result has become not reqresentative, Therefore, identification loward this GAS - MPR gamma spectrometer is veally required, and it also has fo look for the besi countermeasures, in order ta identiyy ats performance exactiy. The idensification was carticd out by checting the hardware and softsvare parts of this equipment. atso by couting several sumples and the standard sourcas. Based on the identification results, it could be knonv that the GAS - MPR gamma spectrometer counting insiability problem occurred because the cooling on its detectar system is offen late and bocutuse the performance of its amplifier beoomes worse or decrease: After its detector to be cooled routinely and with well, alka after the replacement of its amplifier, then the performance of MPR - GAS spectrometer becomes normal again.

Science and Kevword: Problems Tulenification, Gamma Spectrometer RSG-G.4S 


\section{PENDAHULUAN}

Sesuai dengan Perka BAPETEN No.4 tahun 2013, tentang "Proteksi dan Keselamatan Radiasi dalam Pemanfaatan Tenaga Nuklir" bahwa Pemanfaatat radiasi pengion harus memperhatikan keselamatan bagi peralatam, pekerja masyarakat dan lingkungan. Untuk menjamin keselamatan bagi persotil dan sistem RSG-GAS dilengkapi dengan spektrometer ganma dengan spesifikasi scbagai berikut: Merk Canbera, model GC0918, Cryostat 7500 SL. No. Seri 05057508. Pre Amplifier 2002 CSL, Jenis HP Ge, Type Coaxial, Diameter $76 \mathrm{~mm}$, Efficiency $9 \%$. Resolusi 1,8 Kev, jarak detektor dengan sumber $20 \mathrm{~mm}^{\mathrm{D}}$

Secara sederhana spektrometer dapat digambarkan terdiri dari detektor radiasi gamma, rangkaian elektronik penunjang, dan sebuah interface yang disebut Multi Chamel Analyzer (MCA). Seiring dengan perkembangan teknologs rangkaian elektronika, catti daya tegangan tinggi dan rangkaiar MCA kini telah dibuat secara terintegrasi pada onboard slot komputer. Alat ini dilengkapi dengan perangkat lunak khusus (5oftware Maestro 32), pada sperangkat komputer dapat berfungsi sebagai MCA (Multi Channel Analyzer).

Spektrometer gamrua digunakan untuk melakukan analisis zat radioaktif yang memancarkan radiasi gamma. Setiap radionuklida mempunyai tenaga yang tertentu dan bersifat spesifik (Gambar 1) Hal ini digunakan sebagai dasar dalam analisis secara kualitatif Jan kuantitatif. Sesuai dengan salah satu tugas dan fungsi (TUSI) Subbidang Pengendalian Daerah Kerja (PDK) yaitu melakukan pengelolaan laboraturium proteksi radiasi $i^{[4]}$, maka pengoperasian spektrometer gamma di RSG-GAS menjadi tanggung jawab PDK. Alat tersebut terletak di laboratorium spektrometri gamma Bidang Keselamatan dan dipergunakan uniuk menunjang analisis data-data keselamatan radiasi PRSG.

Analisis unsur radioaktif yang secara rutin yang dilakukan oleh subbidang PDK adalah analisis kandungan zat radioaktif pada air pendingin primer, analisis limbah cair, analisis limbah semi cair (resin), analisis sampling udara dan analisis cuplikan-cuplikan lain yang dilakukan secara periodik.
Alat ini telah beroperasi selama 26 tahun scjak 20 Agustus 1997, sehingga secara umum komponen-komponennyat akan mengalami penurunan kemampuannya. Beberapa bulan terakhir alat ini sering tidak stabil, saat sedang melakukan pencacahan tiba-tiba spektrum bergeser bahkan tetkadang spektrumnya rusak. Karena kejadian ini sering berulang jika dibiarkan akan mengganggu sistem pelayanan keselamatan dari subbidang PDK. Oleh karena itu perlu dilakakan identifikasi penyebab ketidak stabilan dan dilakukan penanggulangannya.

Identifikasi penyebab ketidak stabilan yang dilakukan pada Spektrometer gamma tersebut meliputi : pemeriksaan bardware, software dan pelaksanain uji fungsi melalui pencacahan sampel limbah cair dan sumber standar Cs-137 dan Co-60.

Dari hasil identifikasi yang dilakukan dapat diyakinkan bahwa kinerja pencacah MCA tersebut masih berfungsi dengan baik dan memenuhi ketentuan keselamatan kerja.

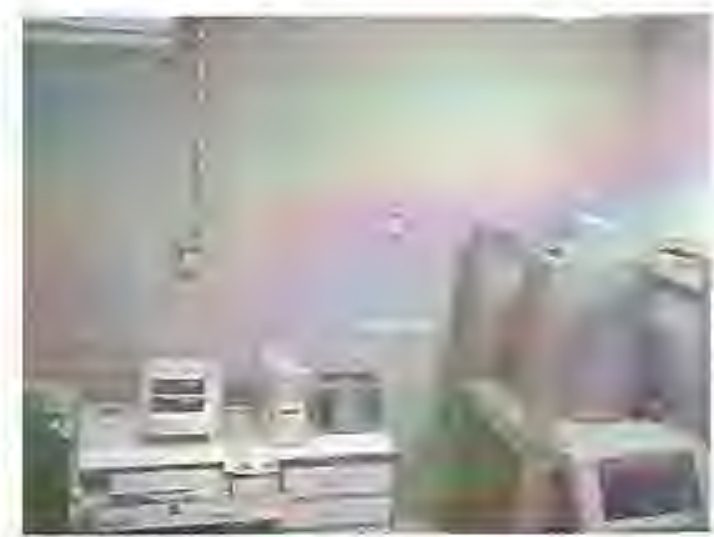

Gambar 1. Sistem spektrometer gamma prsg

Interaksi sinar gamma $(y)$ dengan detekior akan menghasilkan signal pulsa. Tinggi pulsa yang dihasilkan detektor bersesuaian dengan tenaga foton- $\gamma$ yang mengenai detektor. Mekanismenya sebagai berikut, mula-mula pulsa yang dihasilkan detektor akan diperkuat (amplified) dan dibentuk dalam penguat awal dan kemudian penguat (Amplifier)

\section{Penguat Awal}

Alat ini terletak diantara detektor đan penguat yag mempunyat fungsi sebagai berikut:

- Untuk melakukan amplifikasi awal terhadap pulsa keluaran detektor 
- Untuk melakukan pembentukati pulsa pendahuluan

- Untuk mencocokkan impedansi keluaran detektor dengan kabel signal masuk ke penguat

- Lntuk mengadakan perubahan muatan menjadi tegangan pada pulsa keluaran detektor

- Untuk metnurunkari derau

Penguat awal akan lebih baik jika dipasang sedekat mungkin derigan detektor. Padia derektor semi-konduktor biasanya penguat awal sudah merupakan satu kesatuan dengan eryostat detektôt. Ada dua jenis jenis penguat ayal yaitu:

- Yang pertama yang peka terhadap tegangan. penguat jenis ini mempunyai kelebihan dalam bal memiliki nisbah signal/derau yang tinggi, akan tctapi mermpunyai kelemahan dalam hal stabilitas.

- Yang kedua yang peka terhadap muatan

\section{Penguat}

Pulsa keluaran detektor telah diubah dari pulsa muatan ke pulsa tegangan oleh penguat awal. Selanjutrya pulsa tersebut dikirim sebagai masukan dari penguat. Penguat yang dipakai tentu saja penguat yang peka terhadap tegangan yang bisa disebut juga penguat linier. Disini pulsa dipertinggi sampai mencapai amplitudo yang dapat dianalisis dengan alat penganalisis linggi pulsa. Kemamipuan suatu penguat untuk memperkuat pulsa disebut dengan gain. Peguar dirancang. agat dapat memberikan gain yang linier ndan dapat diatur secara sinambung dalam suatu jangkau(range) yang cukup luas. Biasanya disediakan dua tombol pengatur gain penguat, yaitu; Coarse gain untuk mengatue perubahan gain yang besar dan Fine gain untuk mengatur perubahan gain yang kecil dan sinambung. Kebanyakan penguat yatig dipakai dalam spektrometri- $\gamma$ mempunyai gain yang jangkauannya mulai dari lima sampai dua ribu $(5-2000)$

Selain untuk mempertinggi pulsa. penguat juga mempunyai fungsi lain yang sangat penting, yaitu memberi bentuk pulsa, Pulsa ekor yang keluar dari penguat awal dibentuk sekali lagi untuk mendapatkan pulsa yang jauh lebih sempit engan wakta timbal lebih lambat dan waktu jatuh yang lebih cepat. Bentuk pulsa keluaran penguat ditentukan antara lai oelh pertimbangannisbah/signal derau dan kecocokan dengan kemampuan kerja peralatan elektronik berikutnya (penganalisis tinggi pulsa). Kedua kriteria tersebut biasanya bertentangan satu dengan yang lainsehingga bentuk pulsa yang dihasilkan penguat biasanya merupakan kompromi antara bentuk untuk nisbah signal/derauoptimum dan bentuk pulsa yang paling bisa diterima oleh alat penganalisis tinggi puncak.

Bisanya sebuah penguat mempunyai dua macam keluaran yisitu: Unipolar jika menggunakan detektor NaI (TI) dan Bipolar jika mengguanakan detektor semi konduktor atau laju cacah cuplikan tinggi.

Selain its dalam penguat spektroskopi biasanya juga terdapat tombol shaping time yang mengatur waktu pembentukan pulsa. Shaping time berhubungan denga daya pisah sistem. Makin tinggi shaping rime makin tinggi pula daya pisah sistem. Untuk pengukuran spektrometri-y biasanya dipilih shaping time disekitar $1 \mu s$.

Pembentukan pusa dilakukan dengan jalan mendeferensialkan pulsa tersebut. Pendeferensialar pulsa keluaran penguat awal yang berupa pulsa ekor akan menghasilkan suatu pulsa yang mempunyai bagian di bawah garis dasar (zero cross over). Hal ini tidak diinginkan karena dapat menurunkan daya pisah sistem pada laju cacah yang tinggi. Untuk mengatasi persoalan lersebur dilakukan penyesuaian pole-zero. Biasanya pada sebuah penguat diantara tombol-tombolnya terdapat sebuah sekrup kecil untuk melakukan penyesuaian pole-zeto. Penyesuaikan dilakukan dengan memutarmutar sekrup tersebut smbil mengamati pulsa keluaran dalam layar osciloscope ${ }^{\text {IIT, }}$

\section{METODE}

\section{Alat dan bahan}

1. Seperangkat mea lengkap dengan dewar pendingin dan softwarenya

2. Sumber standar co-60 dan es-137

3. Sampel ait kpk 01

4. Merinelli

5. Tool kit

6. Modul amplifier 


\section{Tata Kerja}

1. Melakukan pencacahan sampel

2. Melakukan pencacahan sumber standar co60 dan es-137 sebelum amplifier diganti dengan fungsi hv

3. Melakukan pengujian amplifier dengan menggunakan osiloscop

4. Melakukan pencacahan sumber standar co60 dan cs-137 setelah amplifier dan hv diganti

\section{HASIL}

Hasil pengujian hardware amplifier sebelum dilakukan pencacahan disajikan pada Gambar 2 dan 3. Setelah dilakukan pengesetan pole zero dilanjutkan dengan melakukan pencacahan sampel dan sumber standar disajikan pada Gambar 4, 5, 6, dan 7, sedangkan setelah kondisi stabil ditunjukkan dengan spektrum sumber standar yang disajikan pada Gambar 8 .

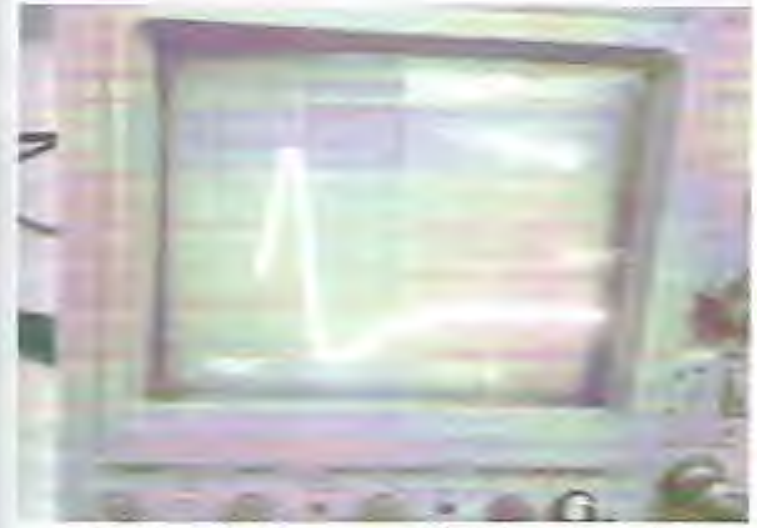

Gambar 2. Kompensasi pole-zero sebelum diatur

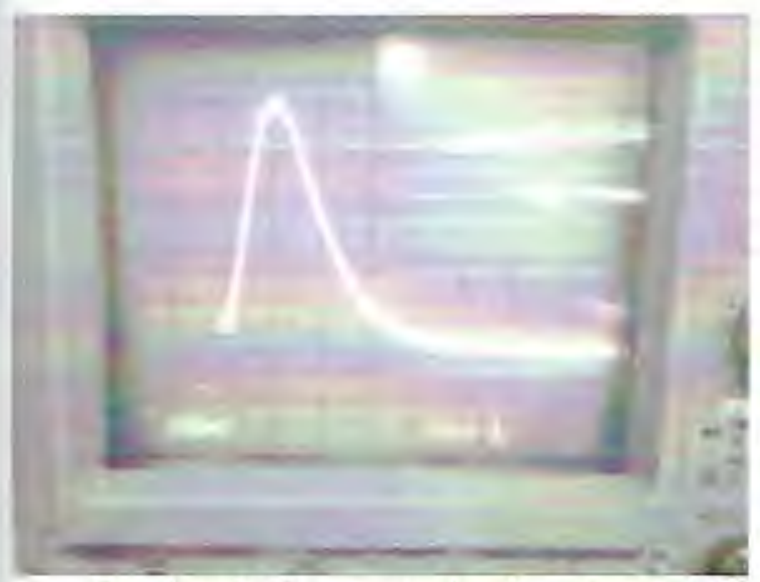

Gambar 3. Kompensasi pole-zero setelah diatur

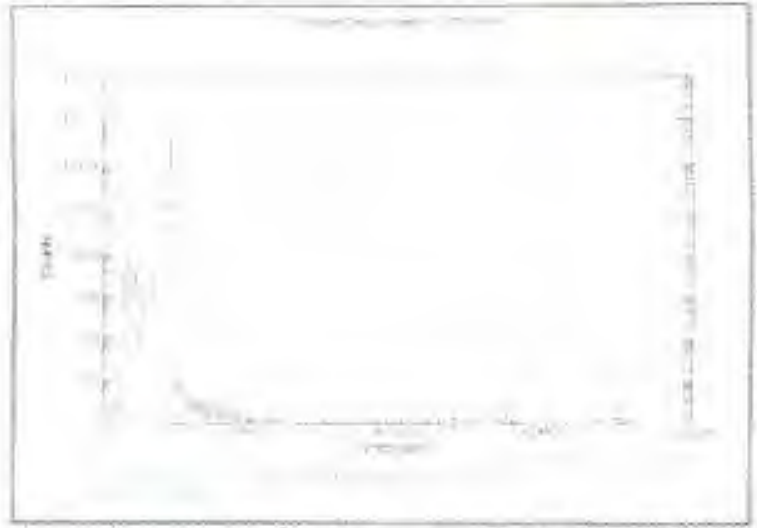

Gambar 4. Spektrum sampel yang tidak stabil

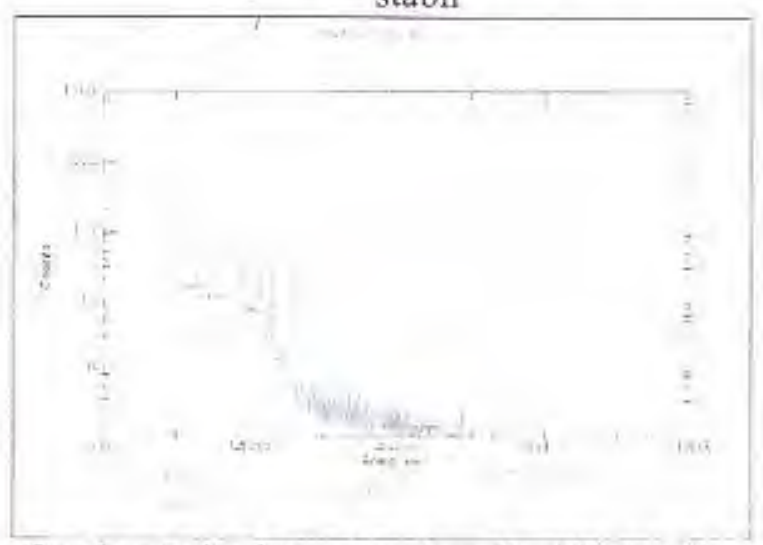

Gambar 5. Spektrum sumber Cs-137 dan Co60 yang tidak stabil

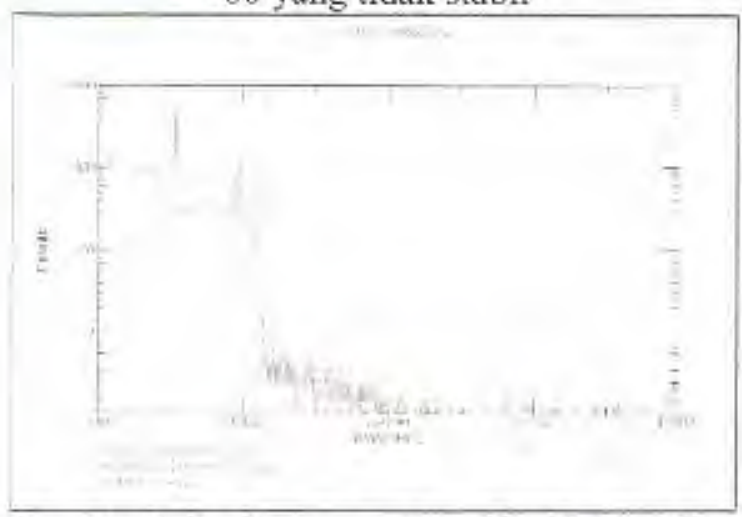

Gambar 6. Spektrum sumber $\mathrm{Cs}-137$ dan $\mathrm{Co}-$ 60 yang tidak stabil

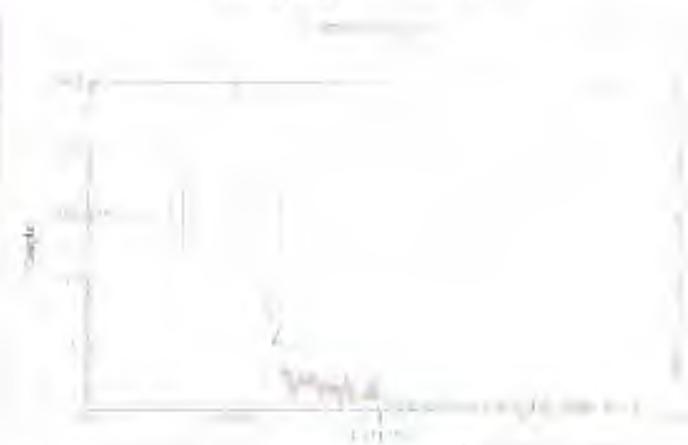

Gambar 7. Spektrum sumber Cs-137 dan Co60 yang tidak stabil 


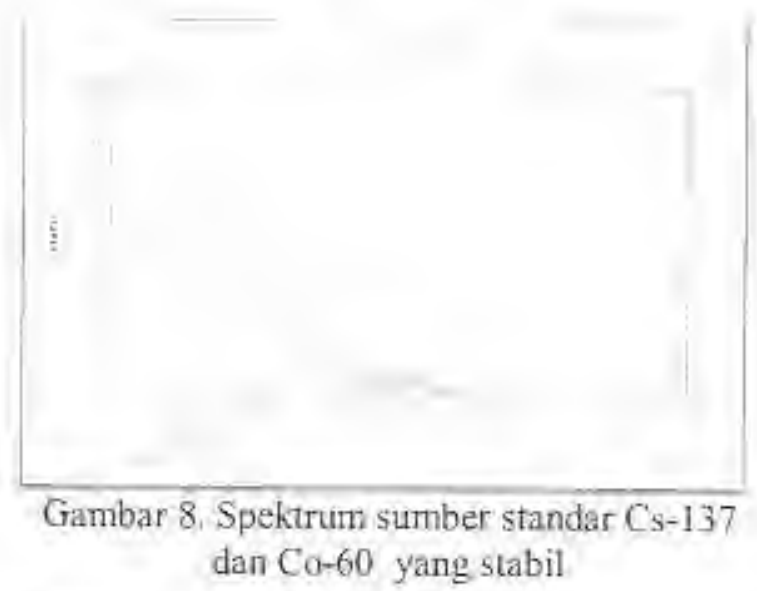

\section{PEMBAHASAN}

Untuk Ineyakinkan balıwa lidak ada permasalahan dengan hardware pertama-tama dilakukan pergujian terhadap keluaran sinyal dari amplifier , Hasil pengujiannya ditunjukkan pada gambar 2, bedasarkan gambat 2 tersebut terlihat bahwa pulsa keluaran penguat awal berupa pulsa ekor yang mempunyai bagian di bawah garis dasar (zero choss over). Hal ini tidak diingukan karena danat menurunkan daya pisah sistem pada laju cacah yang tinggi dim diperolehnya tinggi spektum yang tidak sesuar. Sesuai fungsinya spektrometer gamma bisa digunakan untuk analisis sampel baik analisis kualitatif maupun kuantitatif, jika dengan kondisi ini spektrometer gamma digunakan untuk mencacah maks hasil cacahanuya akan berkurang atau lebih kecil đari yang seharustyya sehingga jika untuk menganalisis kuantitas dari sebuah nuklida maka hasilnyi kurang optimum karena aktivitasnya menjadi lebih kecil. Namun jika untuk analisis kualitatif tidak bermasalah karena spektrum yang terdeteksi retap pada salur (energinya) hanya lebih rendah dari yang seharusnya. Untuk menanggulangi masalah tersebut dengan melakukan penyesuaian polezero, dengan cara mengatur (memutar-mutar) baut pengatur. Setelah dilakukan penyesuaian pole-zero keluaran pulsa dari detektor dibaca dengan osiloscop ditunjukkan pada gambar 3 . berdasarkan gambar 3 tersehut terlihat bahwa keluaran pulsa proposional, bal ini berarti tidak ada kerugian dari pulsa yang dikeluarkan sehingga spektrometer siap digunakan.

Permasalahan yang kedua adalah spektrum yang tidak stabi]. Pada gambar 4 ditunjukkau spektrum yang diperoleh dari cacah sampel limbah cair kpk 01 , berdasarkan gambar 4 rersebur ditunjukkan bahwa spektrum tersebut tidak representatif karena tidak stabil sehingga membentuk spektrum sepcrti yang lidak seharusnya sehingga data tersebut sangatlah lidak valid. Kejadian seperti ini sering berulang, berdasarkan pengamatan yang dilakukan hal ini disebabkan karena keterlambatan dalam melakukan pengisian nitrogen cair yang berfungsi sebagai pendingin sehingga menyebabkan unjuk kerja detektor menjadi tidak stabil. Karena germanium memiliki band gap yang relatif rendah, detektor ini harus didinginkan pada suhu $77^{\circ} \mathrm{K}$ untuk mengurangi arus bocor balik ke tingkat yang dapat diterima, Jika tidak, kebocoran arus gangguan yang dihasilkan akan menghancurkan resolusi energi detektor germanium. Germanium detektor dipasang dalam ruang vakum yang melekat atau dimasukkan ke dalam dewar dan dilindungi dari kelembaban dan kontaminan kondensasi $i^{i}$. Untuk menanggulangi permasalahan ini dengan menjaga agar pengisian nitrogen cair yang berfungsi sebagai pendingin terjadwal dan kontinyu.

Permasalahan yang ketiga adalah disaal sedarng mencacah tiba-tiba muncul spektrum bayangan (bukan spektrum yang sebenarnya) ditunjukkan pada gambar 5. berdasarkan gambar 5 lersebut terlihat bahwa muncul spektrum yang bukan sebenarnya didekat spektrum $\mathrm{C}_{5}-137$ dan $\mathrm{C}_{0}-60$. Hal ini disebabkan karena sistem yang belum stabil Lntuk mengatasi hal tersebut dengan melakukan pemeriksaan pengaturan tegaugan kerja, memeriksa bias suply dan kabel hv. kemudian melakukan pencacahan berulang dengan cara menckan stop, clear dan start secara berulang sampai diperoleh spektrum stabil sesuat dengan kondisi yang diharapkan.

Permasalahan yang keempat adalah disas sedang mencacah tiba-tiba spektrum rusak ditunjukkan pada gambar 6 dan 7 , berdasarkan gambar 6 dan 7 tersebut terlihat bahwa spektrum C $8-137$ dan Co-60 tiba-tiba rusak. Hal int semula diduga disebabkan karena sistem yarng belum stabil. Oleh karena itu untuk mengatasi bal tersebut dengan menuatur amplifier kemudian melakukan pencacahan berulang dengan cara menekan stop, clear dan start secara berulang tetapi lemyata spektrum masilh belum bisa stabil.

Akhirnya dicoba mengganti modul amplifier yang baru. Setelah diganti modul yang baru dan digunakan untuk mencacah 
sumber standar C5-137 dan Co-60 hasil spektrumnya terlihat stabil dan representatif, spektrumnya ditunjukkan pada gambar 8 . Dengan menjaga sistem pendinginan tetap terkondisi dengan baik, melakukan penggantian modul amplifier maka sistem spektrometer gamma rsg-gas kembali berada dalam kondisi normal dan bisa siap digunakan dalam pelayanan analisis sehari-hari.

\section{KESIMPULAN}

Berdasarkan hasil identifikasi yang dilakukan penyebab ketidakstabilan spektrometer gamma RSG-gas dapat disimpulkan sebagai berikut:

1. Ketidak stabilan spektrometer gamma rsggas adalah kurang memadainya sistem pendinginan terhadap detektor HPGe.

2. Melemahnya fungsi amplifier karena faktor aging

3. Untuk menjaga kestabilan spektrometer gamma RSG-gas perlu dikondisikan agar keberlangsungan pendinginan terhadap detektor tetap terjaga.

\section{DAFTAR PUSTAKA}

1. Susetyo. W, spektrometri gamma dan penerapannya dalam analisis pengaktifan neutron, gajah mada university press, (1988).

2. Anonimous, user's manual germanium detectors, canberra.

3. Anonimous, user's manual mca emulator, maestr 32 , ortec.

4. Anonimous, perka bapeten no.4, tentang " proteksi dan keselamatan radiasi dalam pemanfaatan tenaga nuklir", (2013).

5. Sk ka batan: $123 / \mathrm{ka} / \mathrm{viii} / 2007$, tentang " rincian tugas unit kerja lingkungan batan":

6. Juknis pengoperasian mea. 